NASA Technical Memorandum 102115

\title{
Computational Simulation of High Temperature Metal Matrix Composites Cyclic Behavior
}

C.C. Chamis, P.L.N. Murthy, and D.A. Hopkins

National Aeronautics and Space Administration

Lewis Research Center

Cleveland, Ohio

Prepared for the

ASTM Symposium on Thermal and Mechanical Behavior

of Ceramic and Metal Matrix Composites

Atlanta, Georgia, November 7-8, 1988

\section{N/SA}




\section{COMPUTATIONAL SIMULATION OF HIGH TEMPERATURE METAL MATRIX}

\section{COMPOSITES CYCLIC BEHAVIOR}

C.C. Chamis*, P.L.N. Murthy ${ }^{\dagger}$, and D.A. Hopkinst

National Aeronautics and Space Administration

Lewis Research Center

Cleveland, Ohio 44135

\section{SUMMARY}

A procedure was developed and is described which can be used to computationally simulate the cyclic behavior of high temperature metal matrix composites (HTMMC) and its degradation effects on the structural response. This procedure consists of HTMMC mechanics coupled with a multifactor-interaction constituent material relationship and with an incremental iterative nonlinear analysis. The procedure is implemented in a computer code which can be used to computationally simulate the thermomechanical behavior of HTMMC starting from the fabrication process and proceeding through thermomechanical cycling, accounting for the interface/interphase region. Results show that combined thermal/mechanical cycling, the interphase and in situ matrix properties have significant effects on the structural integrity of HTMMC.

\section{INTRODUCTION}

Structural components made from high temperature metal matrix composites (HTMMC) will be subjected to both monotonic and cyclic thermal and mechanical loads. The cyclic loads degrade the composite structural integrity in terms of stiffness and strength. What is of interest is either (1) the degradation rate or (2) the value to which characteristic properties have degraded after a specified number of cycles. Experimental determination of these degradations is frequently prohibitive in cost and may not be tractable because of the numerous contributing factors such as constituent material properties, fabrication process variables, and the continuously changing nonlinear behavior with each cycle.

Recent research by the authors indicates that the degradation can be described at the constituent materials level, including the interphase, by using a multifactor-interaction relationship of product series form. The corresponding degradation at the composite level is described by using composite micro- and macro-mechanics incorporated into a computer code. This computer code is used to computationally simulate the cyclic behavior of HTMMC. The objective of the present paper is to describe the computational procedure and illustrate its application by presenting typlcal results.

\section{GLOBAL STRUCTURAL RESPONSE}

A brief description of global structural analysis provides the background for the need to computationally simulate the thermal/mechanical behavior of

* Senior Aerospace Scientist, ASTM Member.

†Aerospace Research Engineer, Structures Division. 
HTMMC. The process of "computational simulation" is summarized in the following section. A schematic summarizing equations for global structural analysis, through which global structural response variables and local variables are obtained to assess the adequacy of the design, is depicted in figure 1. Computational simulation is used to generate the elements (terms) in the structural matrices: $[M],[C],[K],[D]$, and $\left\{S_{A}\right\}$. The vector $\{F(t)\}$ includes the loading conditions while $\{u\}$ includes the calculated global displacements, $\{\sigma\}$ includes the local stresses and $\omega$ represents the natural frequencies of the structure. Variables with the subscript $A$ denote allowable values of the respective varlables set by the design requirements. Comparable equations are used for thermal analysis where composite micro- and macro-mechanics are used to generate the structure's thermal properties required for heat transfer and for thermal stress analysis. The sections that follow describe the details of the procedure to generate the properties needed for local/global thermostructural analysis of HTMMC.

\section{COMPUTATIONAL SIMULATION OF THERMAL/MECHANICAL PROPERTIES}

For the computational simulation to be representative of the physics of HTMMC behavior, it must account for the fabrication process starting with the constituent materials and ending with the structural component. A schematic depicting the fabrication process of HTMMC is shown in figure 2 . The integrated multiscale computational simulation strategy is shown in figure 3 . The left part of the figure represents the behavior synthesis, while the right part represents the response decomposition. In the synthesis the properties needed for structural analysis are generated, while in the decomposition the local stresses are calculated.

The dependence of the constituent material properties on time, temperature, and stress, is defined in a materials space shown at the bottom center of the figure. The ply stresses are used to calculate the local microstresses (the stresses in the constituents and in the interface). The simulation (synthesis and decomposition) is performed using an incremental-iterative nonlinear analysis where convergence is enforced at every level ( $p l y$, laminate, and global) of the simulation. A detailed description of this simulation including requisite equations is found in reference 1. A stand-alone computer code has been developed to perform the computational simulations from the constituent materials level to the laminate level. This stand-alone code encompasses all the capabilities shown within the dashed line in figure 3 and is identified as METCAN (Metal Matrix Composite Analyzer). METCAN is patterned after and has many of the features of the ICAN computer code (ref. 2).

The various factors, which influence constituent material behavior and ultimately the HTMMC behavior, are incorporated through a multifactorinteraction relationship as shown in figure 4 where the rationale for adopting this type of relationship is summarized. Additional discussion on this relationship and its application to a specific structural component fabricated from HTMMC is found in reference 3. The important points to note in figure 4 are: (1) the individual effects of the thermal and mechanical load cycles $N_{T}, N_{M}$ are explicitly included; (2) the temperature $T$ and the stress $\sigma$ induced by these cycles are also explicitly included; ( 3 ) the combined thermomechanical cyclic effects on the thermomechanical behavior of HTMMC's are, therefore, automatically included; and (4) the various effects are 
normalized with respect to reference properties which are usually taken as room temperature properties.

The important points of the above discussion are (1) METCAN can be used to computationally simulate the high temperature nonlinear behavior of HTMMC's from the fabrication process through service and from global structure response to local constituent response including the interface/interphase regions, and (2) METCAN can be used as a preprocessor to any global structural (thermal) analysis with anisotropic material capability and also as a postprocessor to this same global structural analysis. METCAN is a comprehensive and continuously evolving computer code. In this respect, it is difficult at present to verify all of its predictive capabilities since most of the necessary data do not exist. Even so, the code is continuously validated (compared with other computational predictions) and verified (compared with available or currently acquired experimental data). The room temperature constituent properties used to generate the results that follow are given in Table I. Verification comparisons of room temperature stress/strain response for tungsten/copper HTMMC are shown in figure 5 for two fiber volume ratios. Similar results for graphitel copper, but only at one fiber volume ratio, are shown in figure 6 . The experimental data was obtained by 3 . Diaz, Materials Division, NASA Lewis Research Center. Note that METCAN predicts higher stress and strain to fracture for the graphite/copper which could indicate fiber damage during the fabrication process. Verification and validation comparisons for borsic/titanium metal matrix composite are shown in figure 7 . The agreement is good in all these comparisons, except as already noted. Validation comparisons for room temperature thermal and mechanical properties for a specific graphite fiber (P100)/ copper matrix (CU) HTMMC with four different fiber volume ratios are summarized in table II. These comparisons also show excellent agreement. Though these comparisons are admittedly limited, they do indicate that one can computationally simulate the thermomechanical behavior of HTMMC using METCAN with some confidence.

\section{COMPUTATIONAL SIMULATION OF CYCLIC BEHAVIOR}

The thermal/mechanical cyclic behavior of HTMMC is computationally simulated by using the following procedure:

(1) Calculate the microstresses from global thermal and structural analyses using the respective cyclic loads as inputs to these global analyses. Note the global analyses are performed using finite element analysis of the structural component (top part (undashed) fig. 3 ).

(2) Enter the magnitude of these microstresses and the respective number of thermal and mechanical cycles in the multifactor relationship in figure 4 .

(3) Apply the next cycle loads to the structure and/or laminate and simulate the desired behavior using the incremental-iterative procedure mentioned previously. See references 1 and 3 for more detailed descriptions.

All of the above steps and the required convergences are automatically performed in METCAN and are transparent to the user. 
METCAN predicted longitudinal stress/strain responses for four ply [0/90/90/0] P100/Cu after a specific number of accumulated mechanical cycles are shown in figure 8 . These curves were generated by assuming that: ( 1 ) the limit number of mechanical load cycles was $1 \mathrm{million}$, and (2) the cyclic stress amplitudes were the following ratios of the reference stress (static fracture stress): 85 percent for 100000 cycles, 65 percent for 500000 cycles, and 50 percent for 800000 cycles. It is interesting that the reference curve and the 100000 cycles curve exhibit some nonlinear behavior while the other two curves are practically linear. The important observations from the results shown in figure 8 are: (1) mechanical cyclic loading degrades the cyclic stress magnitude but does not induce any discernable nonlinearities on the stress/strain behavior; and (2) the curves do not start at zero strain because of residuals due to fabrication. Corresponding results for thermal load cycling are shown in figure 9. The number of accumulated thermal load cycles and the temperature range are shown in the figure. Note that the curves start at nonzero strains because of the fabrication residuals already mentioned and because the curve is generated at the elevated temperature. The limit number of thermal cycles was assumed to be 400 for generating these curves. Similarly METCAN predicted thermal cyclic load results are shown in figure 10 for a tungsten/copper HTMMC and in figure 11 for silicon-carbide/titanium-aluminide. The important point to be observed from the thermal cycling load curves is that thermal cycling has severe degradation effects on the endurance of HTMMC's.

\section{SIGNIFICANCE OF THE INTERPHASE AND IN SITU PROPERTIES}

HTMMC either have no metallurgical bond at the interface or develop an interphase as a result of the fiber-matrix reaction (interdiffusion). The micromechanics model in METCAN incorporates the interphase as a separate constituent with independent properties. As such the effects of bond integrity on HTMMC behavior can be evaluated with judicious use of METCAN by using an interphase with suitable properties. Results from one such evaluation are shown in figure 12. As would be expected, both the interface and the in situ properties of the matrix have dramatic effects on the transverse tensile strength of this particular HTMMC. It is noted that the average experimentally measured strength is about $2 \mathrm{ksi}$ which corresponds to the lowest value shown in figure 12. This value was obtained by assuming no interface and ainealed at yield in situ matrix conditions as inputs to METCAN. The important observation in figure 12 is that METCAN can be used to assess the fabrication process as well as the effects of variable constituent in situ behavior on HTMMC performance. For example, the lowest value indicates inadequate fabrication quality and inefficient use of copper as a matrix; while the highest value indicates that there is considerable room for improvement. This type of information is routinely obtained using METCAN, which provides an expedient capability for conducting a variety of parametric studies.

\section{SIMULATION OF COMBINED THERMOMECHANICAL CYCLING AND INTERFACE EFFECTS}

METCAN simulations of the effects of combined thermomechanical cycling are shown in figure 13 for a SIC/Ti HTMMC. Comparisons with experimental data of the half cycle stress-strain response for a unidirectional composite and for an angleplied $[+30]_{2 S}$ laminate are also shown. The dip in the experimental data represents, in part, the onset of excessive nonlinearities caused by high 
intralaminar shear stress in the $30^{\circ}$ plies under displacement control testing. The experimental data were obtained by Dr. B. Lerch, Structures Division, NASA Lewis. The individual load cyclic effects are included for comparison purposes. As can be seen, combined cycling (lower right curves) degrades the mechanical behavior of HTMMC at a faster rate than do elther of the individual loadings or their algebraic superposition. The important observation from the above discussion is that traditional isothermal cyclic data will be inadequate and even misleading for assessing the combined thermomechanical cyclic loading degradation effects on the behavior of HTMMC.

The effects of an interphase on thermal load cycling (fatigue), assuming 400 maximum thermal cycles between 70 and $1000^{\circ} \mathrm{F}$, are shown in figure 14 . Comparisons to those without the interphase at the end points are summarized in the following table.

$\begin{array}{ccr}\begin{array}{c}\text { Number of } \\ \text { accumulated } \\ \text { cycles }\end{array} & \begin{array}{c}\text { Without interphase } \\ \text { stress (strain), } \\ \text { ksi (percent) }\end{array} & \begin{array}{r}\text { With } \\ \text { 5-percent i } \\ \text { stress (str } \\ \text { ksi (percent) }\end{array} \\ 1 & 78(0.44) & 66(0.44) \\ 100 & 69(0.42) & 60(0.42) \\ 200 & 69(0.42) & 49(0.42) \\ 300 & 43(0.43) & 40(0.46)\end{array}$

About the only observation to be made from these results is that the presence of the interphase tends to progressively degrade the stress magnitude at fracture, but not the fracture strain level for all practical purposes. Other tentative observations are: (1) the interphase has negligible effect on the fracture stress magnitude at relatively high thermal cycles, and (2) it has moderate degradation effects (about 16 percent) at relatively low number of thermal cycles. Again, the important conclusion is that METCAN can be used, rather routinely, to evaluate these effects which are complex and difficult to experimentally measure. Also METCAN can be used to aid the planning of strategic experiments to selectively measure some of these effects.

\section{CONCLUDING REMARKS}

The significant conclusions of an investigation to develop a procedure which can be used to computationally simulate the cyclic behavior of HTMMC are as follows:

1. The cyclic behavior of HTMMC can be computationally simulated by using high temperature composite mechanics in conjunction with a multifactorinteraction relationship and with an incremental/interative nonlinear solution procedure.

2. The computational simulation can be performed starting with the fabrication process, through thermomechanical cyclic loadings, and accounting for the interphase.

3. A computer code has been developed to perform these types of computational simulations in an effective and routine manner. 
4. Results from this computer code show that combined thermomechanical cycling degrades the HTMMC structural integrity at a faster rate than the algebraic superposition of the two individual effects.

5. The interphase mainly affects the fracture stress at practically all levels of thermal cycling; it minimally effects the fracture strain, and then only at relatively high numbers of thermal cycles.

6. The interface has dramatic effects on the transverse tensile strength as do the in situ properties of the matrix. The ranges of values of the primitive variables, which contribute to these effects can be quantified.

7. The type of computational simulation (or the respectively computer code) described herein can and should be validated and verified continuously in order to ascertain its predictive adequacy.

\section{REFERENCES}

1. Hopkins, D.A. and Chamis, C.C., "A Unique Set of Micromechanics Equations for High Temperature Metal Matrix Composites," NASA TM-87154, National Aeronautics and Space Administration, Washington, D.C., 1985.

2. Murthy, P.L.N. and Chamis, C.C., Journal of Composites Technology and Research, Vol. 8, No. 1, Spring 1986, pp. 8-17.

3. Chamis, C.C. and Hopkins, D.A., "Thermoviscoplastic Nonlinear Constitutive Relationships for Structural Analys is of High Temperature Metal Matrix Composites," NASA TM-87291, National Aeronautics and Space Administration, Washington, D.C., 1985. 
TABLE I. - ROOM TEMPERATURE CONSTITUENT PROPERTIES USED IN THE CURRENT STUDY

\begin{tabular}{|c|c|c|c|c|}
\hline \multirow[t]{2}{*}{ Property type } & \multicolumn{4}{|c|}{ Fiber } \\
\hline & P 100 & SiCA & Borsic & Tungsten \\
\hline$T_{n \ell},{ }^{\circ} \mathrm{F}$ & 6600 & 4870 & 6000 & 6170 \\
\hline$E_{\ell 11}$, mpsi & 105 & 62 & 58 & 59 \\
\hline$E_{\ell 22}, \mathrm{mpsi}$ & 0.9 & 62 & 58 & 59 \\
\hline $\mathrm{G}_{\ell 12}, \mathrm{mpsi}$ & 1.1 & 23.8 & 29 & 22.7 \\
\hline $\mathrm{G}_{\ell 23}$, mpsi & 0.7 & 23.8 & 29 & 22.7 \\
\hline$v_{\ell 12}$, in./in. & 0.2 & 0.3 & 0.2 & 0.29 \\
\hline$v_{\ell 23}$, in./in. & 0.25 & 0.3 & 0.2 & 0.29 \\
\hline$\alpha_{\ell 1, p p m}$ & -0.9 & 1.8 & 2.8 & 2.5 \\
\hline$\alpha_{\ell 22, \mathrm{ppm}}$ & 5.6 & 1.8 & 2.8 & 2.5 \\
\hline $\mathrm{K}_{\ell 11}$, Btu/hr/in. $/^{\circ} \mathrm{F}$ & 7.5 & 0.75 & 1.9 & 8.3 \\
\hline $\mathrm{K}_{\ell 22}, \mathrm{Btu} / \mathrm{hr} / \mathrm{in} . \mathrm{I}^{\circ} \mathrm{F}$ & 0.75 & 0.75 & 1.9 & 8.3 \\
\hline $\mathrm{S}_{\ell} 1 \mathrm{~T}, \mathrm{Btu} / \mathrm{hr} / \mathrm{in} .1^{\circ} \mathrm{F}$ & 325 & 500 & 510 & 390 \\
\hline $\mathrm{S}_{\ell 11 C}, \mathrm{Btu} / \mathrm{hr} / \mathrm{in} .1^{\circ} \mathrm{F}$ & 200 & 650 & 600 & 390 \\
\hline $\mathrm{S}_{\ell 22 \mathrm{~T}}, 8 \mathrm{tu} / \mathrm{hr} / \mathrm{in} .1^{\circ} \mathrm{F}$ & 25 & 500 & 100 & 390 \\
\hline $\mathrm{S}_{\ell 22 \mathrm{C}}, \mathrm{Btu} / \mathrm{hr} / \mathrm{in} .1^{\circ} \mathrm{F}$ & 25 & 650 & 200 & 390 \\
\hline $\mathrm{S}_{\mathrm{l} 12 \mathrm{~S}}, \mathrm{Btu} / \mathrm{hr} / \mathrm{in} .1^{\circ} \mathrm{F}$ & 25 & 300 & 100 & 236 \\
\hline $\mathrm{S}_{\ell 23 S}, \mathrm{Btu} / \mathrm{hr} / \mathrm{in} . /^{\circ} \mathrm{F}$ & 12.5 & 300 & 100 & 236 \\
\hline
\end{tabular}

\begin{tabular}{|l|r|r|}
\hline \multirow{2}{*}{ Property type } & \multicolumn{2}{|c|}{ Matrix } \\
\cline { 2 - 3 } & Copper & \multicolumn{1}{|c|}{$\mathrm{Ti}$} \\
\hline $\mathrm{T}_{\mathrm{mm}},{ }^{\circ} \mathrm{F}$ & 1980 & 1800 \\
$\mathrm{E}_{\mathrm{m}}, \mathrm{mpsi}$ & 17.7 & 12.3 \\
$\mathrm{~V}_{\mathrm{m}}, \mathrm{in.} / \mathrm{in}$. & 0.3 & 0.32 \\
$\alpha_{\mathrm{m}}, \mathrm{ppm}$ & 9.8 & 4.5 \\
$\mathrm{~K}_{\mathrm{m}}, \mathrm{Btu} / \mathrm{hr} / \mathrm{in.} /{ }^{\circ} \mathrm{F}$ & 19.3 & 0.39 \\
$\mathrm{~S}_{\mathrm{mT}}, \mathrm{ksi}$ & 32 & 130 \\
$\mathrm{~S}_{\mathrm{mC}}, \mathrm{ksi}$ & 32 & 130 \\
$\mathrm{~S}_{\mathrm{mS}}, \mathrm{ksi}$ & 19 & 91 \\
\hline
\end{tabular}


TABLE II. - GRAPHITE/COPPER ROOM TEMPERATURE MECHANICAL AND THERMAL PROPERTIES: COMPARISON OF METCAN PREDICTIONS AND 3-D FINITE ELEMENT ANALYSIS

[P100/Cu at four different fiber volume ratios (FVR).]

\begin{tabular}{|c|c|c|c|c|c|c|c|c|}
\hline \multirow[t]{3}{*}{ Property type } & \multicolumn{8}{|c|}{ FVR } \\
\hline & \multicolumn{2}{|c|}{0.063} & \multicolumn{2}{|c|}{0.2234} & \multicolumn{2}{|c|}{0.466} & \multicolumn{2}{|c|}{0.622} \\
\hline & METCAN & 3-DFEM & METCAN & 3-DFEM & METCAN & 3-DFEM & METCAN & 3-DFEM \\
\hline$E_{\ell 11}$, mpsi & 23.7 & 23.1 & 37.3 & 36.7 & 58.4 & 58.0 & 72.0 & 71.8 \\
\hline$E_{\ell 22}$, mpsi & 13.8 & 14.9 & 10.2 & 11.0 & 6.5 & 6.9 & 4.6 & 5.0 \\
\hline$E_{\ell 33}$, mpsi & 13.8 & 14.9 & 10.2 & 11.0 & 6.5 & 6.9 & 4.6 & 5.0 \\
\hline $\mathrm{G}_{\ell 12}$, mpsi & 5.8 & 6.0 & 4.5 & 4.8 & 3.2 & 3.4 & 2.5 & 2.6 \\
\hline $\mathrm{G}_{\ell 23}, \mathrm{mpsi}$ & 5.6 & 5.8 & 4.2 & 4.5 & 2.8 & 2.7 & 2.1 & 1.8 \\
\hline $\mathrm{G}_{\ell 13}$, mpsi & 5.8 & 5.8 & 4.5 & 4.5 & 3.2 & 2.7 & 2.5 & 1.8 \\
\hline$v_{\ell 12}$, in.lin. & .29 & .30 & .28 & .30 & .25 & .29 & .24 & .28 \\
\hline$v_{\ell 23}$, in.lin. & .30 & .30 & .30 & .26 & .30 & .22 & .30 & .19 \\
\hline$v_{\ell 13}$, in.lin. & .30 & .30 & .30 & .26 & .30 & .22 & .24 & .22 \\
\hline$\alpha_{\ell 11}, p p m$ & 6.8 & 6.6 & 3.3 & 3.7 & 1.0 & 1.40 & .18 & .42 \\
\hline$\alpha_{\ell 22, p p m}$ & 10.4 & 10.5 & 11.0 & 10.9 & 11.2 & 11.1 & 11.1 & 10.9 \\
\hline$\alpha_{\ell 33, \text { ppm }}$ & 10.4 & 10.5 & 11.0 & 10.9 & 11.2 & 11.1 & 11.1 & 10.9 \\
\hline $\mathrm{K}_{\ell 11}$, Btu-in./ ${ }^{\circ} \mathrm{F}-\mathrm{hr}-i n .2$ & 19.7 & 20.6 & 20.6 & 21.6 & 22.0 & 23.2 & 22.8 & 24.0 \\
\hline $\mathrm{K}_{\ell 22}$, Btu-in. $/^{\circ} \mathrm{F}-\mathrm{hr}-\mathrm{in} .2$ & 15.6 & 17.3 & 11.8 & 13.5 & 7.8 & 8.8 & 5.8 & 6.3 \\
\hline $\mathrm{K}_{\ell 23}$, Btu-in. ${ }^{\circ} \mathrm{F}-\mathrm{hr}-\mathrm{in.2}$ & 15.6 & 17.3 & 11.8 & 13.5 & 7.8 & 8.8 & 5.8 & 6.3 \\
\hline
\end{tabular}

$\substack{\text { SYSTEM } \\ \text { OFIIONS } \\ \text { MOTION }}$
$\begin{gathered}\text { CONSTITUTIVE } \\ \text { EQUATION }\end{gathered}$
$\begin{gathered}\text { NATURAL } \\ \text { FREQUENCY } \\ \text { EIGENPROBLEM }\end{gathered}$
FIGURE 1. - OVERVIEW OF STRUCTURAL AMALYSIS.



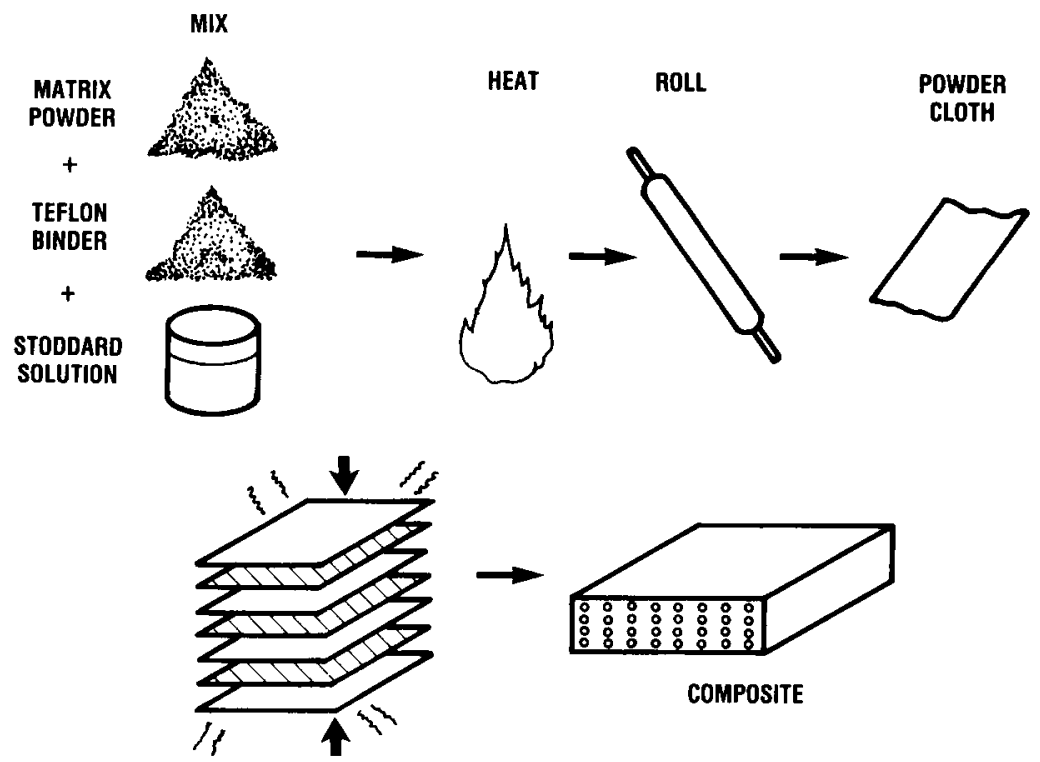

LAY UP AND HOT PAESS

FIGURE 2. - METAL-MATRIX COMPOSITE FABRICATION PROCESS.

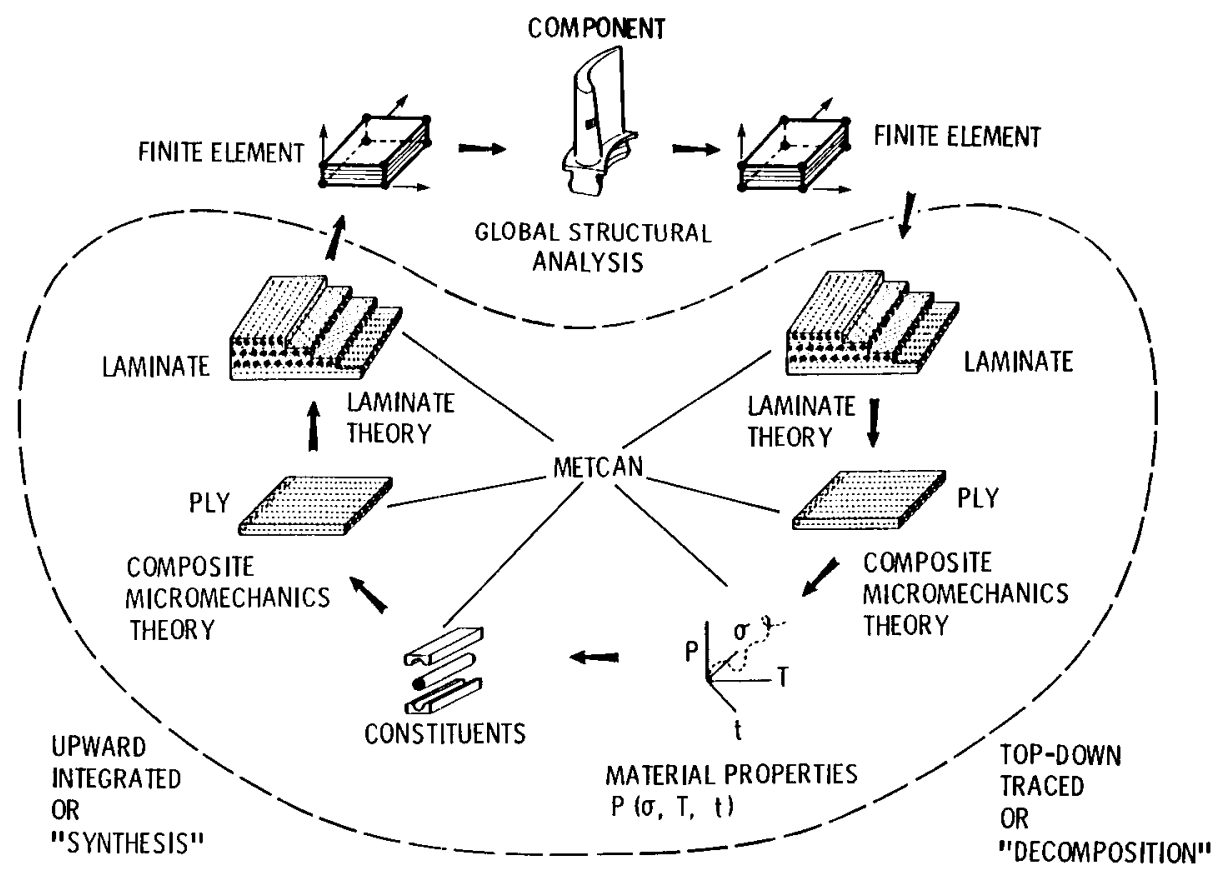

FiguRE 3. - INTEGRATED MULTI-SCALE COMPUTATIOMAL SImULATION. 


$$
\begin{gathered}
\frac{P}{P_{0}}=\left[\frac{T_{F}-T}{T_{F}-T_{0}}\right]^{n}\left[\frac{S_{F}-\sigma}{S_{F}-\sigma_{0}}\right]^{m}\left[\frac{\dot{S}_{F}-\dot{\sigma}_{0}}{\dot{S}_{F}-\dot{\sigma}}\right]^{\ell}\left[\frac{\dot{T}_{F}-\dot{T}}{\dot{T}_{F}-\dot{T}_{0}}\right]^{k}\left[\frac{R_{F}-R}{R_{F}-R_{0}}\right]^{p} \ldots \\
\cdots\left[\frac{N_{M F}-N_{M}}{N_{M F}-N_{M 0}}\right]^{q}\left[\frac{N_{T F}-N_{T}}{N_{T F}-N_{T O}}\right]^{r}\left[\frac{{ }_{F}-t}{t_{F}-t_{0}}\right]^{s} \ldots
\end{gathered}
$$

RATIONALE:

- gradual effects during most range, rapidily degrading near final stages

- representative of the in SITU Behavior fOr fiber. matrix. INTERPhaSe, coating

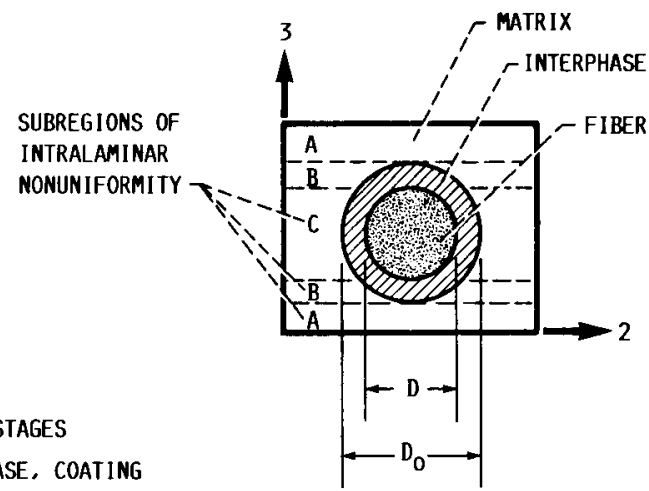

- introduction of primitive Variables (PV)

- consistent in situ representation of all constituent properties in terms of pV

- roOm temperature values for refERENCE PROPERTIES

- continuous interphase growth

- simultaneous interaction of all primitive variables

- adapiability to new materials

- amemable to verification inclusive of all. properties

- readily adaptable to incremental computational simulation

NOTATIONS:

P - PROPERTY; T - TEMPERATURE: $S$ - STRENGTH: $R$ - METALLURGICAL REACTION: $N$ - NUMBER OF CYCLES; $t$ - TIME: OVER DOT - RATE; SUBSCRIPTS: 0 - REFERENCE: $F$ - FINAL; $M$ - MECHANICAL; $T$ - THERMAL

FIGURE 4. - MULTIFACTOR INTERACIION RELATIONSHIP FOR IN SITU CONSIITUENT MATERIAL BEHAVIOR.

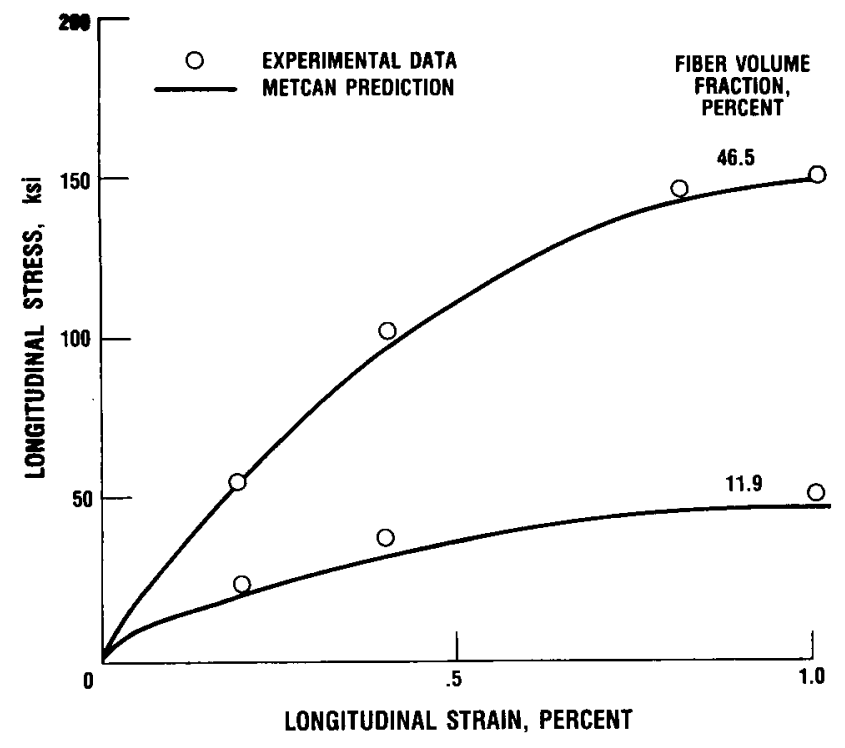

FIGURE 5. - UNIDIRECTIONAL TUNGSTEN/COPPER MMC ROOM TEMPERATURE STRESS-STRAIN RESPONSE.

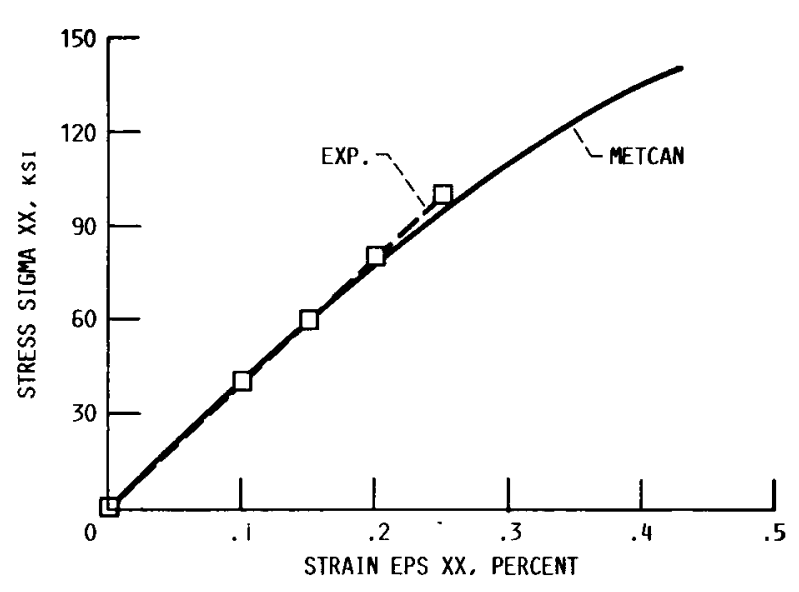

FIGURE 6. - Gr/CU COMPOSITES ROOM IEMPERATURE STRESSSTRAIN BEHAVIOR (UNIDIRECTIONAL LAMIMATE AT . 4 FVR). 


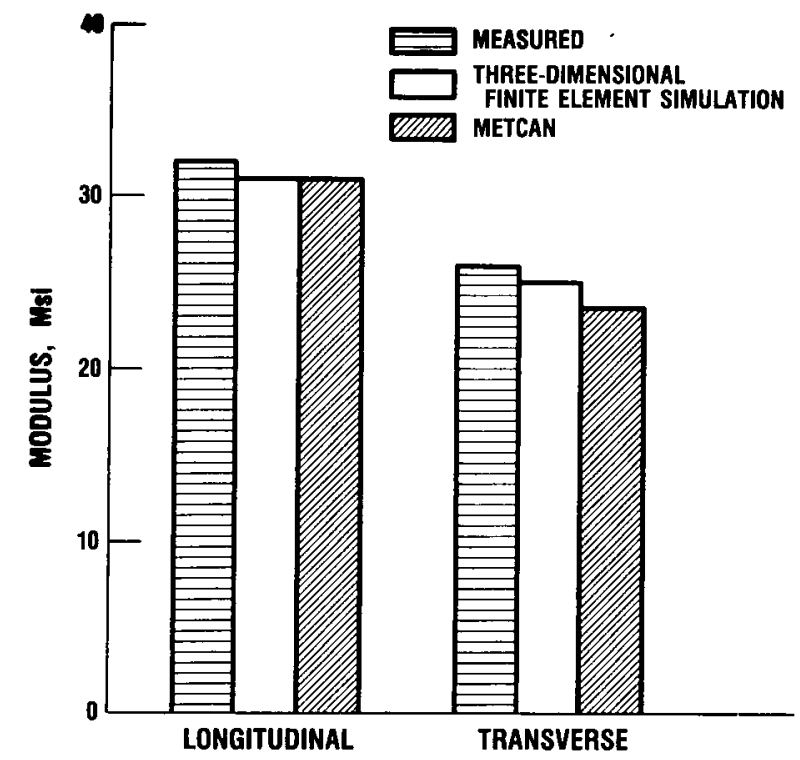

FIGURE 7. - UNIDIRECTIONAL BORSIC/TITANIUM MMC ELASTIC MODULI AT ROOM TEMPERATURE.

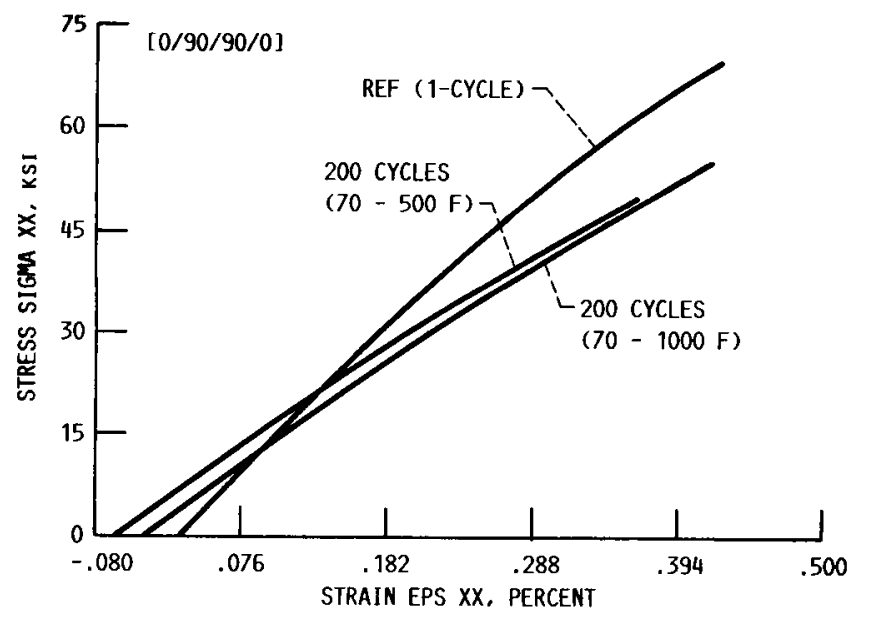

FIGURE 9. - THERMAL CYCLIC EFFECTS OF P100/CU COMPOSITE (AT . 4 FVR).

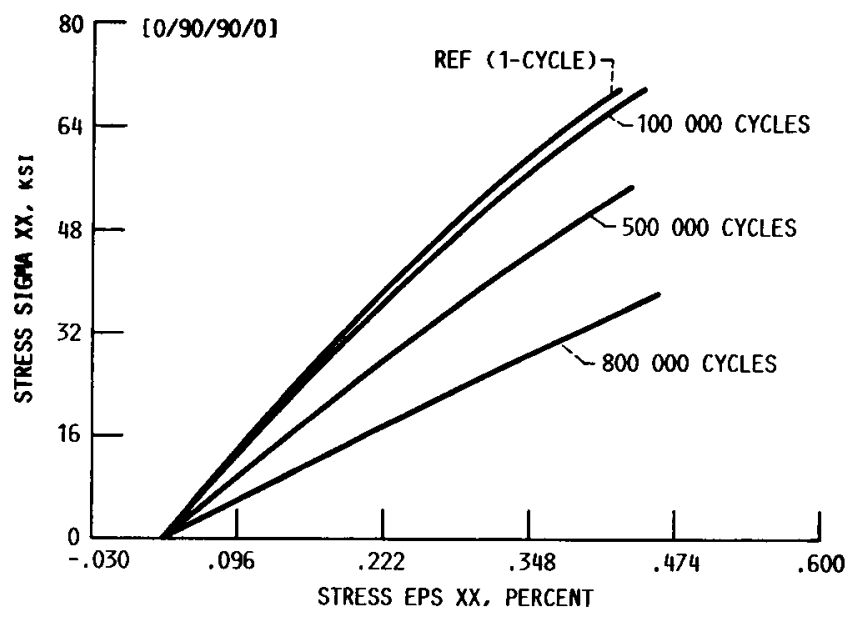

FIGURE 8. - MECHANICAL CYCLIC LOAD EFFECTS (P100/CU AT .4 FVR).

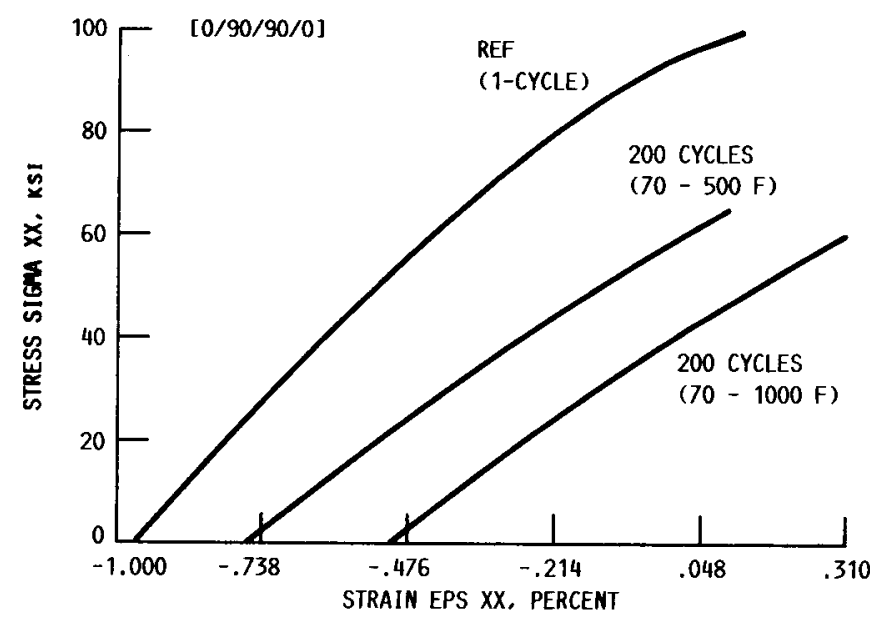

FIGURE 10. - THERMAL CYCLIC EFFECTS OF TUNG/CU COMPOSITE (AT . 4 FVR). 


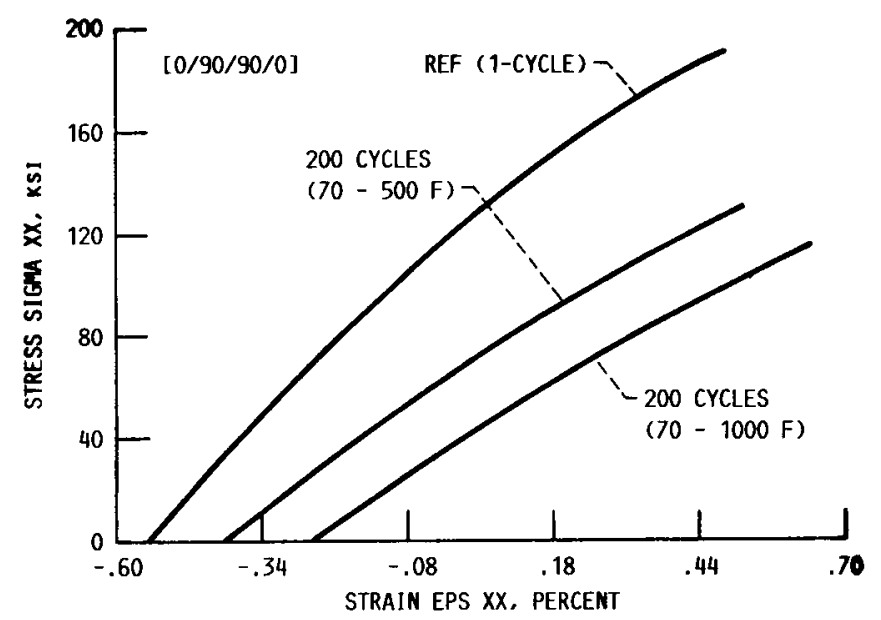

FIGURE 11. - THERMAL CYCLIC EFFECTS OF SICa/TI 15 COMPOSITE (AT .4 FVR).

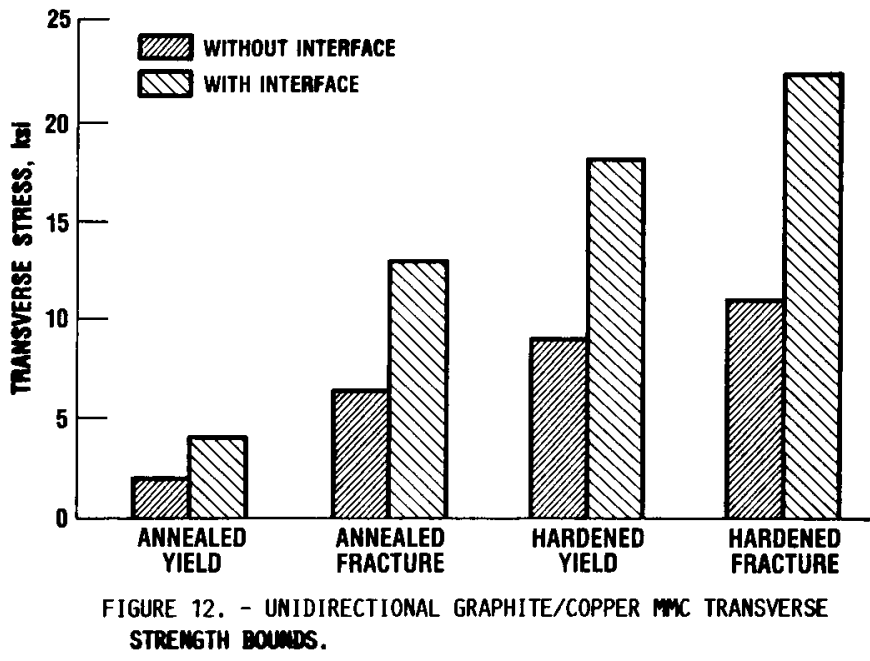




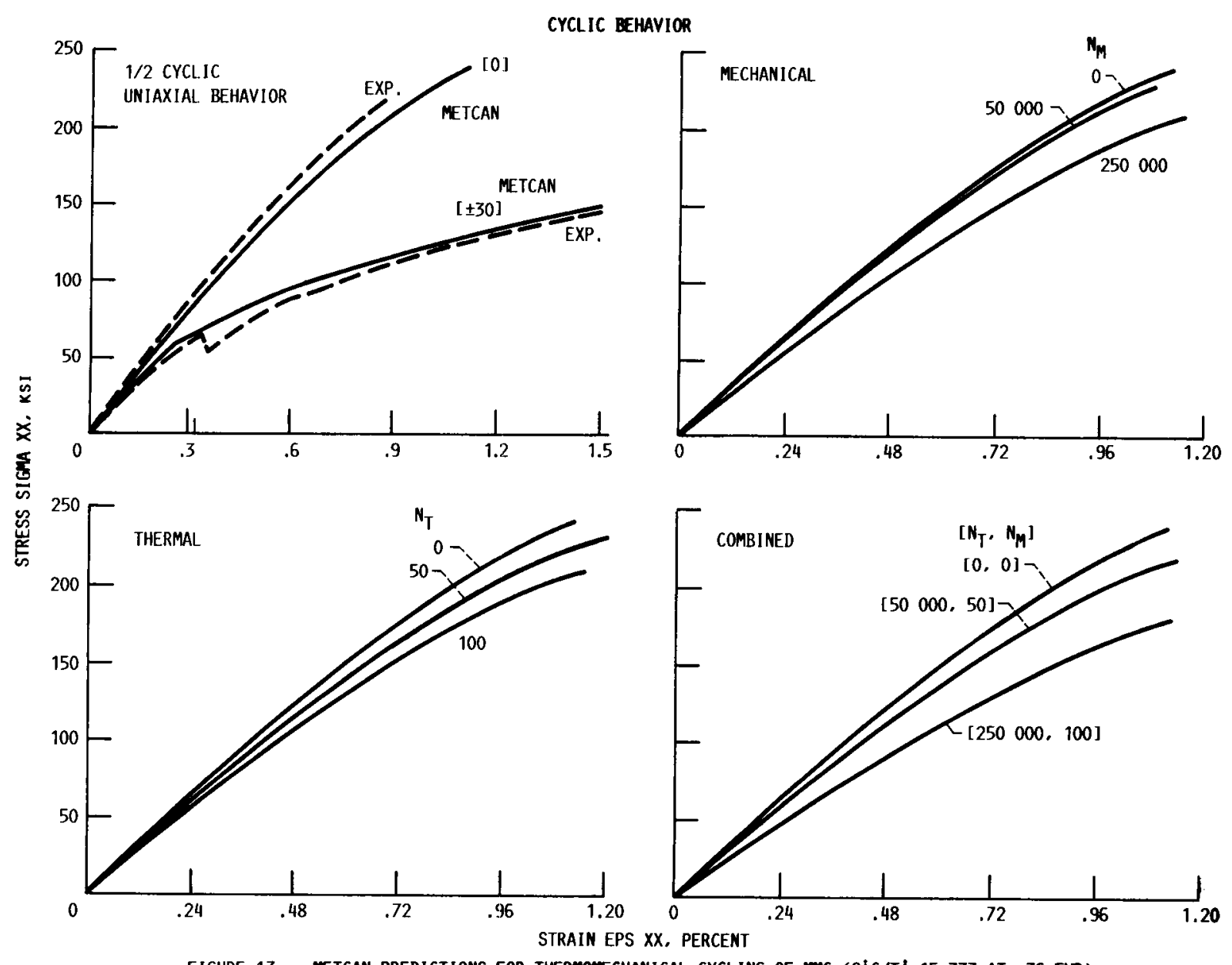

FIGURE 13. - METCAN PREDICTIONS FOR THERMOMECHANICAL CYCLING OF mC (SIC/TI 15333 AT .36 FVR).

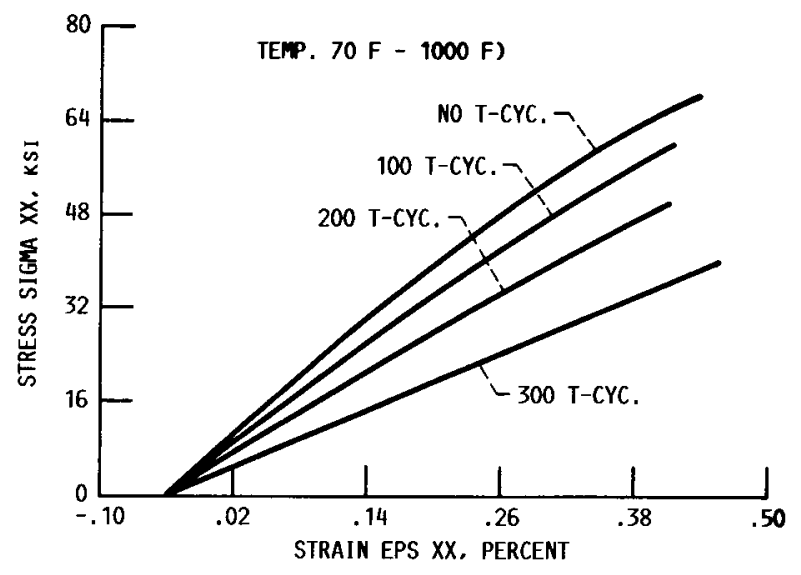

FIGURE 14. - [0/90/90/0] P100/CU WITH 5 PERCENT INTERPHASE THERMAL FATIGUE EFFECTS. 


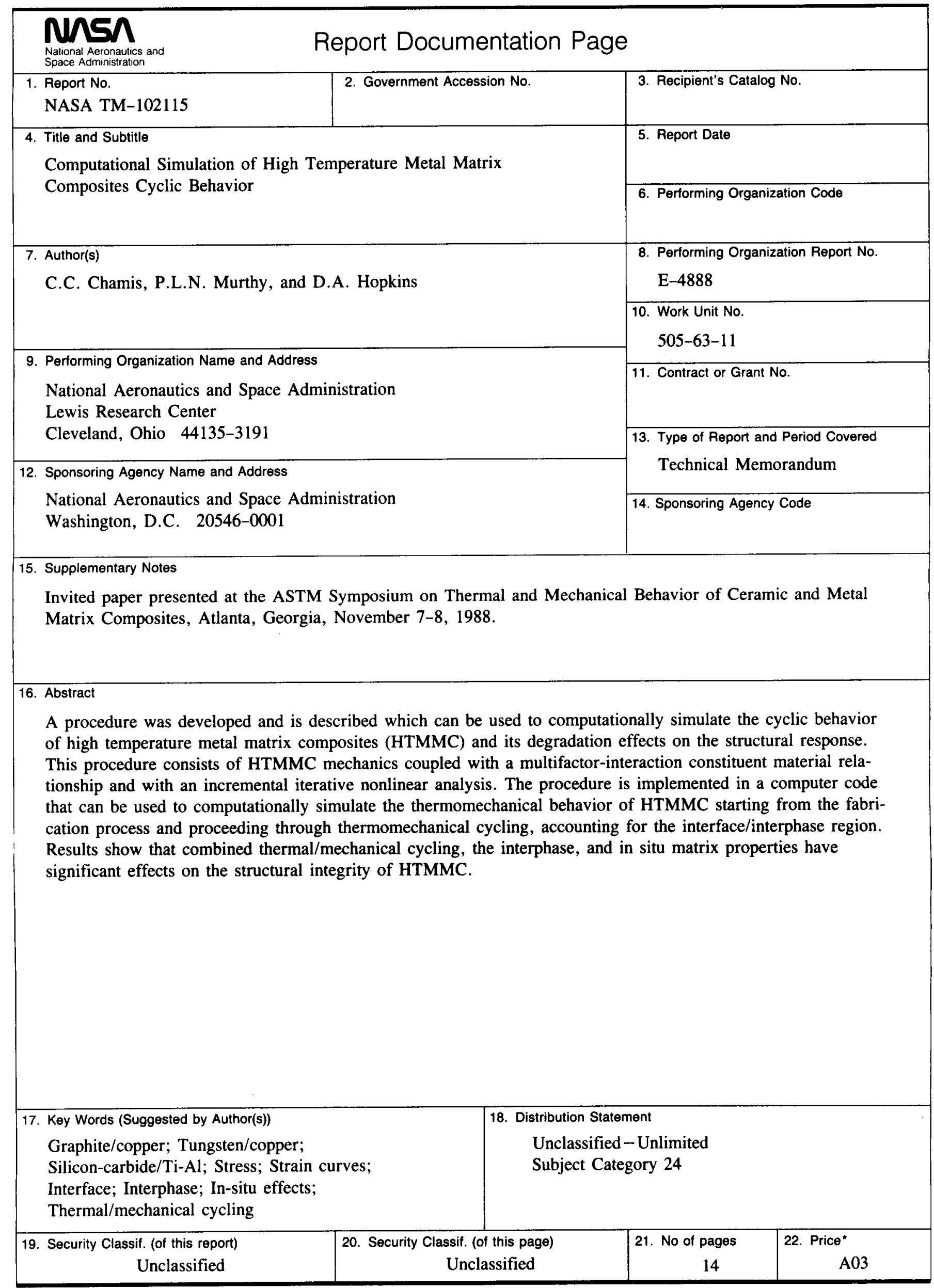

